K при кольцевидной гранулеме

Харчилава М. Г., Хайрутдинов В. Р.., Белоусова И. Э., Самцов А. В.

Военно-медицинская академия им. С. М. Кирова Министерства обороны Российской Федерации

194044, Российская Федерация, г. Санкт-Петербург, Суворовский просп., д. 63, лит. «3»

Кольцевидная гранулема (КГ) представляет собой дерматоз неясной этиологии, который имеет отличительные клинические и гистологические особенности. В данной статье мы представляем современные сведения об этиологии, патогенезе, клинической картине и патоморфологических признаках КГ, а также проводим дифрференциальную диагностику КГ с заболеваниями, имеющими схожую клиническую и гистологическую картину.

Ключевые слова: кольцевидная гранулема, этиология, патогенез, патоморфологические признаки

Конфрликт интересов: авторы заявляют об отсутствии потенциального конфрликта интересов, требующего раскрытия в данной статье.

Для цитирования: Харчилава М. Г., Хайрутдинов В. Р., Белоусова И. Э., Самцов А. В. Клинико-патоморфологические изменения кожи при кольцевидной гранулеме. Вестник дерматологии и венерологии. 2019;95(2):8-14. https://doi.org/10.25208/0042-4609-2019-95-2-8-14 


\title{
Clinical and pathological changes in the skin with granuloma annulare
}

\author{
Maya G. Kharchilava, Vladislav R. Khairutdinov*, Irena E. Belousova, Alexey V. Samtsov
}

S. M. Kirov Military Medical Academy, Ministry of Defence of the Russian Federation Suvorovsky prospekt, 63, letter "3", Saint Petersburg, 194044, Russian Federation

Granuloma annulare (GA) is a dermatosis of unknown etiology, which has distinctive clinical and histological features. In this article, we present current information about the etiology, pathogenesis, clinical picture and pathomorphological signs of GA, as well as conduct differential diagnosis of GA with diseases that have a similar clinical and histological picture.

Keywords: granuloma annulare, etiology, pathogenesis, pathomorphological signs

Conflict of interest: the authors state that there is no potential conflict of interest requiring disclosure in this article.

For citation: Kharchilava M. G., Khairutdinov V. R., Belousova I. E., Samtsov A. V. Clinical and pathological changes in the skin with granuloma annulare. Vestnik Dermatologii i Venerologii. 2019;95(2):8-14. https://doi.org/10.25208/00424609-2019-95-2-8-14 
Кольцевидная гранулема (КГ) - доброкачественное неинфекционное воспалительное заболевание кожи, наиболее часто клинически проявляющееся папулами, расположенными кольцевидно, и гистологически характеризующиеся гранулематозным воспалением. КГ впервые была описана в 1895 г. английским дерматологом T.C. Fox. Позднее, в 1902 г., R. Crocker, проанализировав все описанные на тот момент случаи, предложил объединить их термином «кольцевидная гранулема». КГ встречается у представителей всех возрастных групп и не имеет расовых различий. В некоторых исследованиях приведены данные, что КГ наблюдается чаще у женщин, чем у мужчин (соотношение женщины:мужчины = 2:1). Высыпания могут встречаться на любом участке кожного покрова, но излюбленными локализациями являются тыльные поверхности стоп, кистей, разгибательные поверхности конечностей, боковые поверхности туловища [1-3].

Несмотря на многочисленные исследования, на сегодняшний день этиология КГ остается неизвестной, а патогенез недостаточно изучен. В современной литературе описаны заболевания, которые можно ассоциировать с КГ: сахарный диабет [4-6], злокачественные опухоли (лимфома Ходжкина, неходжкинские лимфомы, лейкозы, аденокарцинома) [7-11], заболевания щитовидной железы [12], нарушения липидного обмена [13] и вирусные инфекции (опоясывающий герпес, вирус Эпштейна - Барр, вирусные гепатиты В и С, туберкулез) [14-17]. В качестве триггерных фракторов рассматривается татуаж [18], укусы насекомых [19], вакцинация [20], мезотерапия [21], в литературе описаны случаи появления очагов КГ в местах разрешения высыпаний опоясывающего герпеса [22, 23]. Также КГ может быть вызвана приемом лекарственных препаратов, таких как аллопуринол, топирамид, ингибиторы ФНО-альфра [24-26].

Можно выделить несколько теорий развития КГ. В 1977 г. Dahl и соавт. провели исследование, в котором участвовали 58 пациентов с диагнозом КГ. Авторы рассматривали в качестве причины развития КГ утолщение, окклюзию или другие повреждения сосудов, которые могут привести к деградации соединительной ткани [27]. Umbert и соавт. в 1976 г. предположили, что изменение клеточного иммунитета может лежать

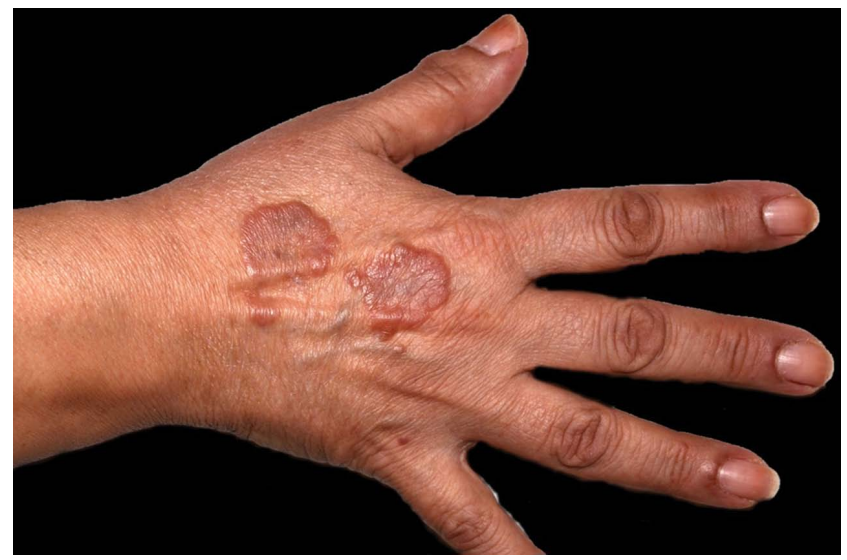

Рис. 1. Локализованная форма КГ. Узелки розового цвета с фиолетовым оттенком, расположенные в виде кольцевидных очагов

Fig. 1. Localized form of granuloma annulare. Pink nodules with a violet tinge located in the form of annular foci в основе патогенеза КГ, в частности, активация макрофрагов и фрибробластов приводит к деградации соединительной ткани [30]. В некоторых исследованиях была описана первичная дегенерация коллагена, активизирующая макрофраги с ответной гранулематозной реакцией. Friedman и Winkelmann описали семейный случай КГ [32]. Knoell наблюдал КГ у монозиготных близнецов [33]. Возможно, это указывает на наследственную природу части случаев этой патологии.

Клиническая классификация КГ включает в себя множество вариантов: локализованную (рис. 1), генерализованную кольцевидную, диссеминированную папулезную, атипичную генерализованную, подкожную, перфорирующую. Локализованная фрорма КГ зачастую связана с травмой, вакцинацией и укусами насекомых и встречается в 75 \% описанных случаев. Данная форма представлена узелками розового цвета с фиолетовым оттенком, которые располагаются в виде дугообразных очагов от 0,5 до 5 см в диаметре. Центр очагов со временем проседает и приобретает окраску нормальной кожи. Наблюдается локализованная форма преимущественно у лиц молодого возраста. Излюбленными локализациями являются тыльные поверхности кистей и стоп, фраланги пальцев, разгибательные поверхности локтевых и коленных суставов. Локализованная форма склонна к самопроизвольному разрешению в течение 2 лет. Генерализованные варианты КГ (рис. 2, 3), включающие в себя генерализованную кольцевидную, диссеминированную папулезную и атипичную генерализованную фрормы, в большинстве случаев ассоциированы с системными заболеваниями. Клинически диссеминированные и генерализованные фрормы представлены многочисленными очагами поражения (более 10 очагов) в нескольких анатомических областях. Встречаются в 8-15 \% случаев, преимущественно у людей старше 50 лет. Высыпания обычно симметричные, локализуются в области боковых поверхностей груди и живота, представлены множественными рассеянными или сгруппированными пятнами и папулами синюшно-красного или красно-коричневого цвета. В отличие от локализованной формы, высыпания не склонны к самопроизвольному разрешению. Подкожная форма КГ (рис. 4), также известная как псевдоревматоидная или глубокая, чаще встречается у детей в возрасте от 2

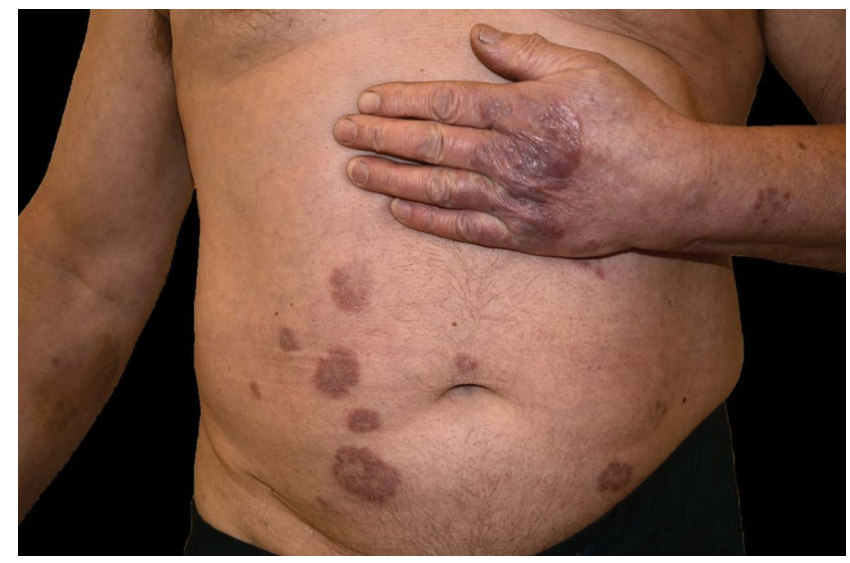

Рис. 2. Генерализованная формма КГ. Множественные сливающиеся между собой узелки, склонные к кольцевидному расположению Fig. 2. Generalized form of granuloma annulare. Multiple merging nodules prone to ring-shaped arrangement 
до 6 лет и характеризуется плотными безболезненными подвижными узлами размерами от 1 до 4 см в диаметре. Эта фрорма КГ встречается преимущественно в области волосистой части головы и нижних конечностей. Высыпания при подкожной фрорме могут разрешаться самостоятельно. Перфорирующая КГ встречается редко, преимущественно у детей и лиц молодого возраста. Высыпания могут быть ограниченными или распространенными. Клиническая картина при перфорирующей форме КГ представлена узелками от 1 до 4 мм, сливающимися в крупные бляшки. Узелки имеют пупкообразное вдавление. В центре некоторых из них можно различить роговую пробку, при надавливании на которую выделяется желатиноподобное содержимое. Высыпания всегда разрешаются с образованием атрофических рубцов [34-39, 50].

Диагностика типичных форм КГ не представляет труда и проводится, как правило, на основании клинической картины. При атипичных фрормах КГ могут возникнуть диагностические трудности, в таком случае необходимо проведение биопсии кожи, подтверждающей гистологические особенности заболевания.

Гистологическая картина при КГ характеризуется наличием некробиотической гранулемы, в центре которой наблюдается дезорганизация пучков коллагена и отложение муцина. В настоящее время в литературе описано 4 гистологических подтипа КГ: палисадный, интерстициальный («непалисадный»), саркоидный и смешанный. Winkelmann описал 207 случаев КГ, из них $71 \%$ составил интерстициальный подтип, 26 \% - палисадный, 3 \% - саркоидный и смешанный подтипы. Во всех случаях обнаруживался лимфогистиоцитарный периваскулярный инфильтрат. При электронной микроскопии выявлены гистиоцитарные и макрофрагальные васкулопатии с дегенерацией мелких сосудов. Отложения муцина были выявлены в $94 \%$ случаев [43].

Палисадный подтип характеризуется наличием гранулематозного инфильтрата в сосочковой дерме. Центральная зона инфильтрата состоит из некробиотического коллагена, окруженного гистиоцитами в виде палисада и различным количеством лимсроцитов (рис. 5). При интерстициальном подтипе гистиоциты расположены между фррагментированными коллагеновыми волокнами и вокруг кровеносных сосудов в сосочковой и сетчатой дерме (рис. 6). При саркоидном подтипе гистиоциты рассеяны в дерме и гиподерме без палисадного узора, могут обнаруживаться эпителиоидные гистиоциты, что может имитировать гранулемы саркоидного типа. Наличие муцина может помочь в постановке правильного диагноза (рис. 7) [3, 40, 42, 43]. При подкожной форме КГ очаг некробиоза локализуется глубоко в дерме или гиподерме.

Диффреренциальный диагноз в таком случае проводится с ревматоидными узелками.

Диффреренциальная диагностика КГ проводится с заболеваниями, которые гистологически могут иметь схожие признаки: палисадный нейтрофильный и гранулематозный дерматит (ПНГД), интерстициальный гранулематозный дерматит (ИГД), кольцевидная эластолитическая гигантоклеточная гранулема (КЭГГ) и ревматоидные узелки (табл. 1). Гистологическая картина ИГД характеризуется наличием диффузно расположенного инфильтрата различной плотности, который может затрагивать верхний и глубокий слои дермы (что

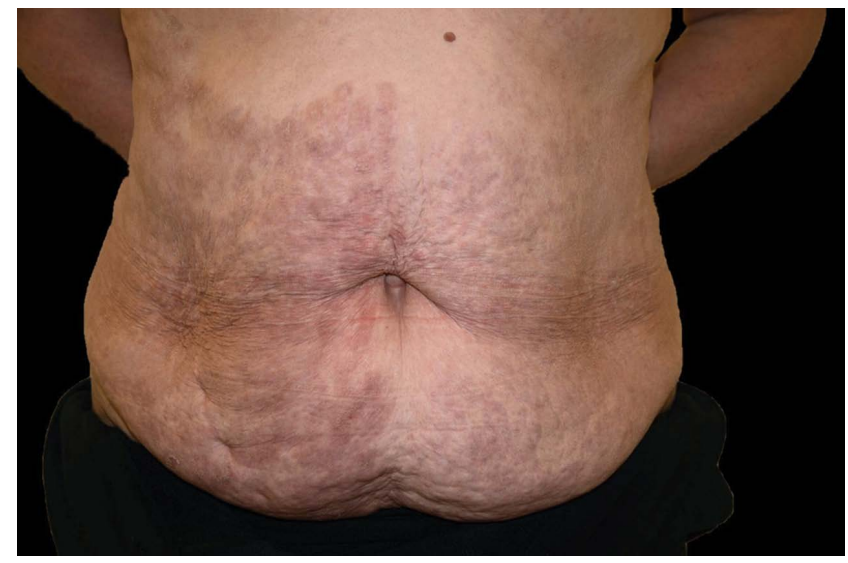

Рис. 3. Диссеминированная КГ. Множественные очаги, имеющие сетчатый характер, не склонные к кольцевидному расположению Fig. 3. Disseminated granuloma annulare. Multiple foci of a reticular nature not prone to ring-shaped arrangement

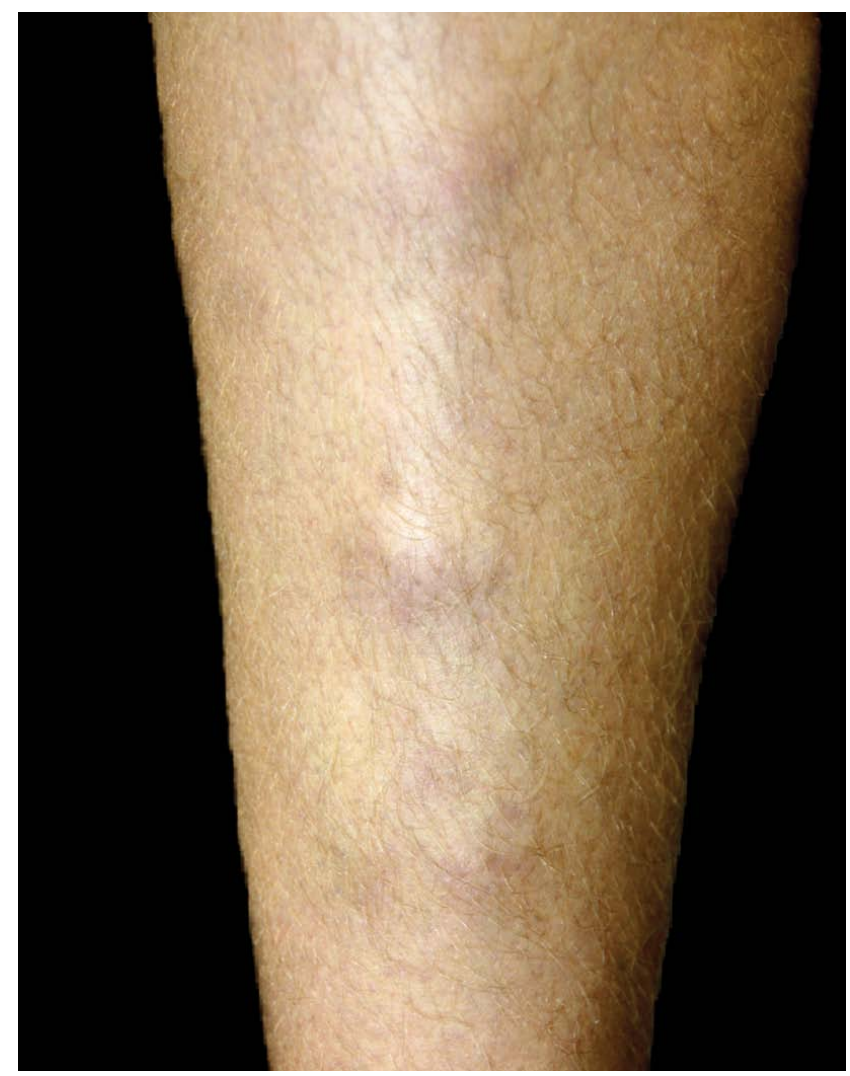

Рис. 4. Подкожная форма КГ. Плотные безболезненные подвижные узлы Fig. 4. Subcutaneous form of granuloma annulare. Dense, painless and mobile nodes

позволяет дифференцировать ИГД от интерстициального подтипа КГ, при котором глубокий слой не поражается). Воспалительный инфильтрат состоит из эпителиоидных гистиоцитов, которые располагаются между пучков коллагена или вокруг коллагеновых волокон в виде частокола, что вызывает образование щелей (пустых пространств). Такая гистологическая картина получила название «плавающие знаки». Эозинофилы и нейтрофилы встречаются редко. Васкулит отсутствует. Отложение муцина, как правило, минимально или отсутствует [40, 44-46]. 


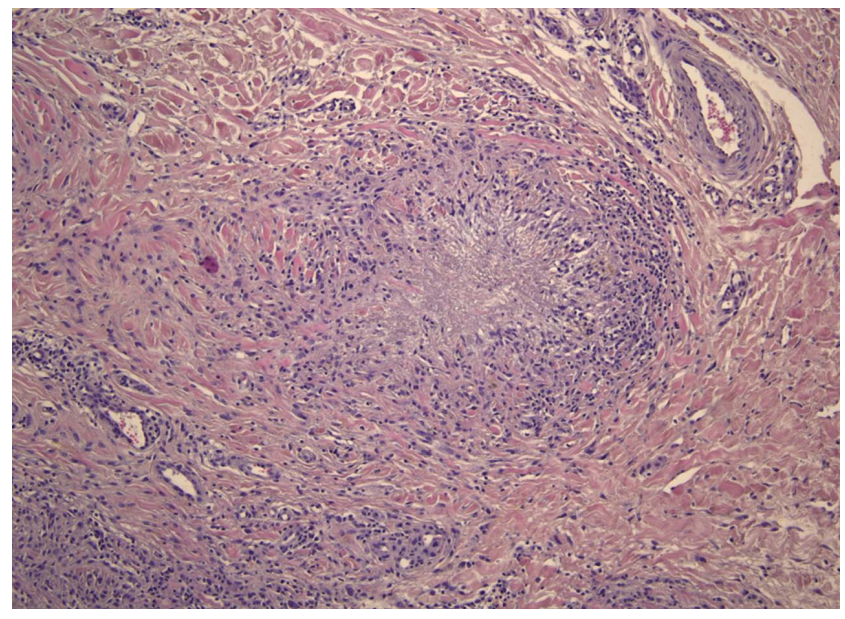

Рис. 5. Палисадный подтип КГ характеризуется наличием гранулематозного инфильтрата в дерме. Центральная зона гранулемы представлена очагом некробиоза коллагена, окруженного гистиоцитами в виде палисада Fig. 5. Palisade granuloma annulare characterized by the presence of granulomatous infiltrate in the dermis. The central zone of the granuloma is represented by

a focus of collagen necrobiosis surrounded by histiocytes in the form of a palisade

На ранних стадиях ПНГД гистологическая картина характеризуется выраженным периваскулярным инфрильтратом из лимфоцитов, нейтрофилов и гистиоцитов. На более поздних стадиях развития ПНГД наблюдаются зоны некробиотического коллагена, окруженные многоядерными гигантскими клетками и лимфоцитами. Гистиоциты располагаются вокруг измененных коллагеновых волокон в виде частокола (палисада). Может визуализироваться небольшое количество муцина [46-48].

При КЭГГ обнаруживаются плотные гранулематозные инфильтраты в верхней части дермы, состоящие из гигантских клеток и гистиоцитов. В зоне инфильтрата визуализируются слегка утолщенные и базофильно окрашенные эластические волокна, которые фрагоцитируются гигантскими клетками. При КГ гигантские клетки отсутствуют. В отличие от кольцевидной гранулемы, некробиотические изменения и отложения муцина обычно отсутствуют $[49,50]$.

При патоморфологическом исследовании ревматические узелки характеризуются крупными очагами дегенерации коллагена, которые, в отличие от КГ, рас-

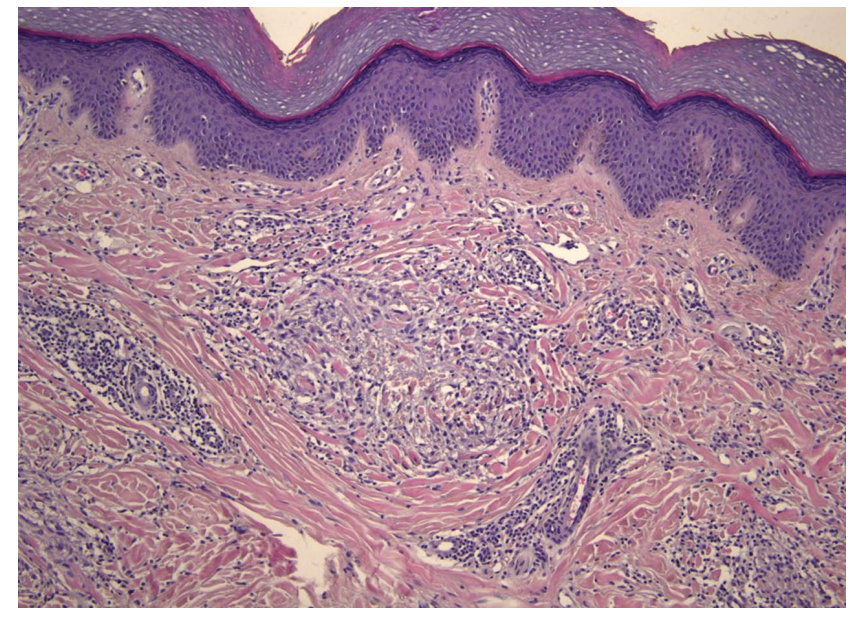

Рис. 6. При интерстициальном подтипе КГ гистиоциты расположены между фрагментированными коллагеновыми волокнами в сосочковой и сетчатой дерме

Fig. 6. Interstitial granuloma annulare is characterized by histiocytes located between fragmented collagen fibers in the papillary and reticular dermis

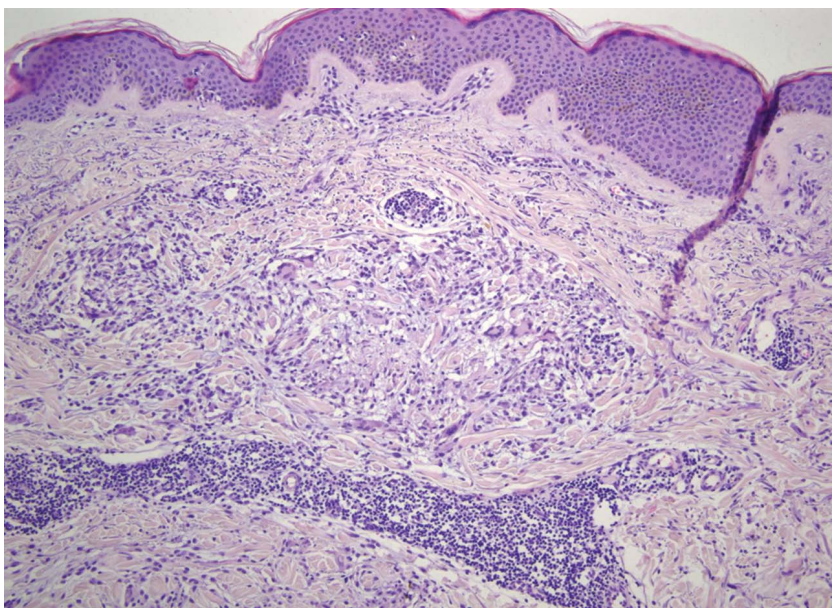

Рис. 7. Саркоидный подтип КГ. В гранулеме присутствуют гигантские многоядерные клетки и гистиоциты, напоминающие эпителиоидные клетки Fig. 7. Sarcoid granuloma annulare. The granuloma contains giant multinucleated cells and histiocytes resembling epithelioid cells

Таблица 1. Гистопатологическая сравнительная характеристика кольцевидной гранулемы, палисадного нейтрофильного и гранулематозного дерматита, интерстициального гранулематозного дерматита, ревматоидных узелков и кольцевидной эластолитической гигантоклеточной гранулемы

Table 1. Histopathological comparative characteristics of granuloma annular, palisade neutrophilic and granulomatous dermatitis, interstitial granulomatous dermatitis,

rheumatoid nodules and annular elastoplastic giant cell granuloma

\begin{tabular}{|c|c|c|c|c|}
\hline $\mathrm{K} \Gamma$ & ПНГД & ИГД & Py & КЭГГ \\
\hline $\begin{array}{c}\text { Некробиотический под- } \\
\text { тип - очаг дезорганизации } \\
\text { коллагена, окруженный гис- } \\
\text { тиоцитами в виде палисада; } \\
\text { интерстициальный подтип- } \\
\text { гистиоциты и муцин располо- } \\
\text { жены между коллагеновыми } \\
\text { волокнами; при саркоидном } \\
\text { подтипе могут наблюдаться } \\
\text { эпителиоидные гистиоциты. } \\
\text { Отложение муцина } \\
\text { в областях гранулематозного } \\
\text { воспаления }\end{array}$ & $\begin{array}{c}\text { Выраженное нейтро- } \\
\text { фильное воспаление. } \\
\text { Зоны некробиоти- } \\
\text { ческого коллагена, } \\
\text { окруженные много- } \\
\text { ядерными гигантскими } \\
\text { клетками } \\
\text { и лимфоцитами. } \\
\text { Наблюдается пораже- } \\
\text { ние сосудов. } \\
\text { Отложение муцина, как } \\
\text { правило, минимально } \\
\text { или отсутствует }\end{array}$ & $\begin{array}{c}\text { Воспалительный инфильтрат } \\
\text { состоит из эпителиоидных } \\
\text { гистиоцитов, которые распола- } \\
\text { гаются между пучков колла- } \\
\text { гена или вокруг коллагеновых } \\
\text { волокон в виде частокола, что } \\
\text { вызывает образование щелей } \\
\text { («плавающие знаки»). } \\
\text { Эозинофилы и нейтрофилы } \\
\text { встречаются редко. } \\
\text { Васкулит отсутствует. } \\
\text { Отложение муцина, как правило, } \\
\text { минимально или отсутствует }\end{array}$ & $\begin{array}{l}\text { Очаги фибрино- } \\
\text { идной дегенера- } \\
\text { ции коллагена } \\
\text { в глубоких отделах } \\
\text { дермы, окружен- } \\
\text { ных макрофагами. } \\
\text { В стенках сосудов } \\
\text { наблюдаются } \\
\text { воспалительные } \\
\text { и дистрофические } \\
\text { изменения. } \\
\text { Отложение муцина } \\
\text { отсутствует }\end{array}$ & $\begin{array}{c}\text { Плотные гранулематозные } \\
\text { инфильтраты в верхней } \\
\text { части дермы, состоящие } \\
\text { из гигантских клеток } \\
\text { и гистиоцитов. } \\
\text { В зоне инфильтрата визуали- } \\
\text { зируются слегка утолщенные } \\
\text { и базофильно окрашенные } \\
\text { эластические волокна, } \\
\text { которые фрагоцитируются } \\
\text { гигантскими клетками. } \\
\text { Муцин и зоны некробиоза } \\
\text { коллагена отсутствуют }\end{array}$ \\
\hline
\end{tabular}

Примечание: КГ — кольцевидная гранулема; ПНГД — палисадный нейтросильный и гранулематозный дерматит; ИГД — интерстициальный гранулематозный дерматит Ру — ревматоидные узелки; КЭГГ — кольцевидная эластолитическая гигантоклеточная гранулема.

Note: КГ — granuloma annulare; ПНГД — palisade neutrophilic granulomatous dermatitis; ИГД — interstitial granulomatous dermatitis; PУ — rheumatoid nodules; КЭГГ — annular elastolytic giant cell granuloma. 
положены глубоко в дерме или в подкожной жировой клетчатке, преимущественно гистиоцитарной клеточной инфильтрацией с примесью плазматических клеток и лимфоцитов. В стенках сосудов наблюдаются воспалительные и дистрофические изменения. Отложение муцина отсутствует (табл. 1) [46, 47].

На сегодняшний день КГ является часто встречающимся заболеванием. В большинстве случаев диагноз удается установить на основании клинической картины, но не всегда она бывает специфична. В связи с этим пациентам с предварительным диагнозом КГ необходимо проведение биопсии кожи с последующим гистологическим исследованием. В статье мы описали основные гистологические подтипы КГ и привели данные о диффреренциальной диагностике КГ с другими заболеваниями.

\section{Литература/References}

1. Studer E. M., Calza A. M., Saurat J. H. Precipitating factors and associated diseases in 84 patients with granuloma annulare: a retrospective study. Dermatology. 1996;193:364-368.

2. Lukacs J., Schliemann S., Elsner P. Treatment of generalized granuloma annulare — a systematic review. J Eur Acad Dermatol Venerol. 2015 Aug;29(8):1467-1480.

3. Piette E. W., Rosenbach M. Granuloma annulare: Clinical and histologic variants, epidemiology, and genetics. J Am Acad Dermatol. 2016 Sep;75(3):457-465.

4. Haim S., Friedman-Birnbaum R., Shafrir A. Generalized granuloma annulare: relationship to diabetes mellitus as revealed in 8 cases. Br J Dermatol. 1970;83:302-305.

5. Muhlemann M. F., Williams D. R. Localized granuloma annulare is associated with insulin-dependent diabetes mellitus. $\mathrm{Br} J$ Dermatol. 1984;111:325-329.

6. Meier-Ewert H., Allenby C. F. Grannulomaannulare and diabetes mellitus. Arch Dermatol Forsch.1971;241:194-198.

7. Li A., Hogan D. J., Sanusi I. D., Smoller B. R. Granuloma annulare and malignant neoplasms. Am J Dermatopathol. 2003;25:113-116.

8. Cohen P. R. Granuloma annulare, relapsing polychondritis, sarcoidosis, and systemic lupus erythematosus: conditions whose dermatologic manifestations may occur as hematologic malignancy-associated mucocutaneous paraneoplastic syndromes. Int J Dermatol. 2006;45:70-80.

9. Shimizu S., Yasui C., Tsuchiya K. Atypical generalized granuIoma annulare associated with two visceral cancers. J Am Acad Dermatol. 2006;54(5 Suppl):S236-S238.

10. Setoyama M., Kerdel F. A., Byrnes J. J., Kanzaki T. Granuloma annulare associated with Hodgkin's disease. Int J Dermatol. 1997:36:445-448.

11. Schwartz R. A., Hansen R. C., Lynch P. J. Hodgkin's disease and granuloma annulare. Arch Dermatol. 1981;117:185-186.

12. Vazquez-Lopez F., Gonzalez-Lopez M. A., Raya-Aguado C., PerezOliva N. Localized granuloma annulare and autoimmune thyroiditis: a new case report. J Am Acad Dermatol. 2000;43(5 Pt 2):943-945.

13. Watanabe S., Tanaka M., Kobayashi K. et al. Remission of generalized erythematous granuloma annulare after improvement of hyperlipidemia and review of the Japanese literature. Dermatol Pract Concept. 2014:4:97-100.

14. Chang S. E., Bae G. Y., Moon K. C., Do S. H., Lim Y. J. Subcutaneous granuloma annulare following herpes zoster. Int $\mathrm{J}$ Dermatol. 2004:43:298-299.

15. Ruocco E., Baroni A., Cutri F. T., Filioli F. G. Granuloma annulare in a site of healed herpes zoster: Wolf's isotopic response. J Eur Acad Dermatol Venereol. 2003;17:686-688.

16. Ma H. J., Zhu W. Y., Yue X. Z. Generalized granuloma annulare associated with chronic hepatitis B virus infection. J Eur Acad Dermatol Venereol. 2006;20:186-189.
17. Granel B., Serratrice J., Rey J. et al. Chronic hepatitis C virus infection associated with a generalized granuloma annulare. J Am Acad Dermatol. 2000;43(5 Pt 2):918-919.

18. Gradwell E., Evans S. Perforating granuloma annulare complicating tattoos. Br J Dermatol. 1998;138:360-361.

19. Takayama K., Satoh T., Yokozeki H. Papular granuloma annulare with subcutaneous granulomatous reaction induced by a bee sting. Acta Derm Venereol. 2008;88:519-520.

20. Kakurai M., Kiyosawa T., Ohtsuki M., Nakagawa H. Multiple lesions of granuloma annulare following BCG vaccination: case report and review of the literature. Int J Dermatol. 2001;40:579-581.

21. Strahan J. E., Cohen J. L., Chorny J. A. Granuloma annulare as a complication of mesotherapy: a case report. Dermatol Surg. 2008 Jun;34(6):836-838. DOI: 10.1111/j.1524-4725.2008.34156.x. Epub 2008 Mar 31.

22. Krahl D., Hartschuh W., Tilgen W. Granuloma annulareperforans in herpes zoster scars. J Am Acad Dermatol. 1993;29(5 Pt 2):859-862.

23. Guill M. A., Goette D. K. Granuloma annulare at sites of healing herpes zoster. Arch Dermatol. 1978;114:1383.

24. Singh S. K., Manchanda K., Bhayana A. A., Verma A. Allopurinol induced granuloma annulare in a patient of lepromatous leprosy. J Pharmacol Pharmacother. 2013;4:152-154.

25. Cassone G., Tumiati B. Granuloma annulare as a possible new adverse effect of topiramate. Int J Dermatol. 2014;53:259-261.

26. Ahmad U., Li X., Sodeman T., Daboul I. Hepatitis C virus treatment with pegylated interferon-alfa therapy leading to generalized interstitial granuloma annulare and review of the literature. Am J Ther. 2013;20:585-587.

26. Dahl M. V., Ullman S., Goltz R. W. Vasculitis in granuloma annulare: histopathology and direct immunofluorescence. Arch Dermatol. 1977; 113:463-467.

27. Smith M. D., Downie J. B., DiCostanzo D. Granuloma annulare. International Journal of Dermatology. 1997;36(5):326-333.

28. Buechner S. A., Winkelmann R. K., Banks P. M. Identification of T-cell subpopulations in granuloma annulare. Arch Dermatol. 1983 Feb;119(2):125-128.

29. Umbert P., Belcher R. W., Winkelmann R. K. Lymphokines (MIF) in the serum of patients with sarcoidosis and cutaneous granuloma annulare. Br J Dermatol. 1976;95:481-485.

30. Piette E. W. Rosenbach M. Granuloma annulare: Pathogenesis, disease associations and triggers, and therapeutic options. J Am Acad Dermatol. 2016 Sep;75(3):467-479

31. Friedman S. J., Winkelmann R. K. Familial granuloma annulare. Report of two cases and review of the literature. J Am Acad Dermatol. 1987 Mar;16(3 Pt 1):600-605.

32. Knoell K. A. Efficacy of adalimumab in the treatment of generalized granuloma annulare in monozygotic twins carrying the 8.1 ancestral 
haplotype. Arch Dermatol. 2009 May;145(5):610-611. DOl: 10.1001/archdermatol.2009.92

33. Asai J. What is new in the histogenesis of granulomatous skin diseases? J Dermatol. 2017 Mar;44(3):297-303.

34. Dabski K., Winkelmann R. K. Generalized granuloma annulare: Clinical laboratory findings in 100 patients. J Am Acad Dermatol. 1989;20:39-47.

35. Zhong W., Shao Y., Ye T., Li J., Yu B., Dou X. Perforating granuloma annulare: a case report and literature review. J Eur Acad Dermatol Venereol. 2016 Jul;30(7):1246-1247. D0l: 10.1111/jdv.13174

36. Alves J., Barreiros H., Bártolo E. Perforating Granuloma Annulare - An Unusual Subtype of a Common Disease. Healthcare (Basel). 2014 Sep 4;2(3):338-345.

37. Boudhir H., Bouhllab J., Rimani M., Senouci K., Hassam B. Generalized annular granuloma. Presse Med. 2014 Nov;43(11):1299-1301.

38. Keimig E. L. Granuloma Annulare. Dermatol Clin. 2015 Jul;33(3):315-329.

39. Rosenbach M., English J.C. Reactive Granulomatous Dermatitis: A Review of Palisaded Neutrophilic and Granulomatous Dermatitis, Interstitial Granulomatous Dermatitis, Interstitial Granulomatous Drug Reaction, and a Proposed Reclassification. Dermatol Clin. 2015 Jul;33(3):373-387.

40. Kallioinen M., Sandberg M., Kinnunen T., Oikarinen A. Collagen synthesis in granuloma annulare. J Invest Dermatol. 1992 Apr;98(4):463-468.

41. Umbert P., Winkelmann R. K. Histologic, ultrastructural and histochemical studies of granuloma annulare. Arch Dermatol. 1977 Dec;113(12):1681-1686.

42. Dabski K., Winkelmann R.K. Generalized granuloma annulare: histopathology and immunopathology. Systematic review of 100 cases and comparison with localized granuloma annulare. J Am Acad Dermatol. 1989 Jan;20(1):28-39.

43. Huizenga T., Kado J. A., Pellicane B., Borovicka J., Mehregan D. R., Mehregan D.A. Interstitial granulomatous dermatitis and palisaded neutrophilic granulomatous dermatitis. Cutis. 2018 May;101(5):E19-E21.

44. Tebeica T., Voicu C., Patterson J. W., Mangarov H., Lotti T., Wollina U. et al. Interstitial Granulomatous Dermatitis. Open Access Maced J Med Sci. 2017 Jul 21;5(4):543-544.

45. Terziroli Beretta-Piccoli B., Mainetti C., Peeters M. A., Laffitte E. Cutaneous Granulomatosis: a Comprehensive Review. Clin Rev Allergy Immunol. 2018 Feb;54(1):131-146.

46. Wick M. R. Granulomatous \&histiocytic dermatitides. Semin Diagn Pathol. 2017 May;34(3):301-311.

47. Kalen J. E., Shokeen D., Ramos-Caro F., Motaparthi K. Palisaded neutrophilic granulomatous dermatitis: Spectrum of histologic findings in a single patient. JAAD Case Rep. 2017 Sep 8;3(5):425-428.

48. Ragaz A., Ackerman A. B. Is actinic granuloma a specific condition? Am J Dermatopathol. 1979;1:43-50.

49. Barnhill R. L., Goldenhersh M. A. Elastophagocytosis: a non-specific reaction pattern associated with inflammatory processes in sun-protected skin. J Cutan Pathol. 1989;16:199-202.

50. Барбинов В. В., Чирский В. С., Тарасенко Г. Н., Барбинов Д. В. Результаты изучения патоморфоза красного плоского лишая на основе определения его современных гистологических признаков. Российский журнал кожных и венерических болезней. 2014;(3):42-48. [Barbinov V. V., Chirsky V. S., Tarasenko G. N., Barbinov D. V. Results of the study of pathomorphosis of lichen planus based on the definition of its modern histological features. Russian Journal of Skin and Venereal Diseases. 2014;(3):42-48. (In Russ.)]

\section{$\overline{\text { Информация об авторах }}$}

Майя Гиоргиевна Харчилава - ассистент кафедры кожных и венерических болезней Военно-медицинской академии им. С. М. Кирова Министерства обороны Российской Федерации; тел. +7 (981) 882-55-55

Владислав Ринатович Хайрутдинов* - доцент кафедры кожных и венерических болезней Военно-медицинской академии им. C. М. Кирова Министерства обороны Российской Федерации; e-mail: haric03@list.ru

Ирена Эдуардовна Белоусова - д.м.н., профессор кафедры кожных и венерических болезней Военно-медицинской академии им. С. М. Кирова Министерства обороны Российской Федерации

Алексей Викторович Самцов - заведующий кафедрой кожных и венерических болезней Военно-медицинской академии им. С. М. Кирова Министерства обороны Российской Федерации

\section{Information about the authors}

Maya G. Kharchilava - Research Assistant, Department of Skin and Venereal Diseases, S. M. Kirov Military Medical Academy, Ministry of Defence of the Russian Federation; tel.: +7 (981) 882-55-55

Vladislav R. Khairutdinov* - Assoc. Prof., Department of Skin and Venereal Diseases, S. M. Kirov Military Medical Academy, Ministry of Defence of the Russian Federation; e-mail: haric03@list.ru

Irena E. Belousova - Dr. Sci. (Med.), Prof., Department of Skin and Venereal Diseases, S. M. Kirov Military Medical Academy, Ministry of Defence of the Russian Federation

Alexey V. Samtsov - Head of the Department of Skin and Venereal Diseases, S. M. Kirov Military Medical Academy, Ministry of Defence of the Russian Federation 